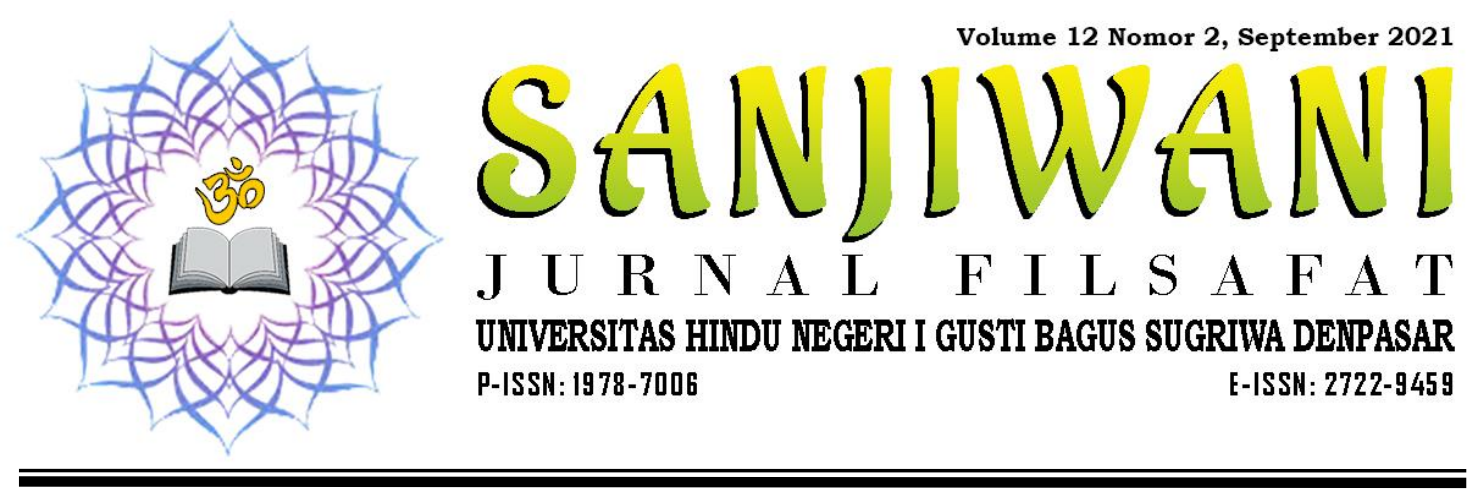

\title{
Tujuan Manusia dan Jalan untuk Mencapainya Menurut Advaita Vedanta
}

\author{
Anak Agung Raka Asmariani \\ Universitas Hindu Negeri I Gusti Bagus Sugriwa Denpasar \\ agungrakaasmariani@gmail.com
}

\begin{tabular}{|ll|}
\hline Keywords: & ABSTRACT \\
\hline $\begin{array}{l}\text { Human Purpose; } \\
\text { Advaita Vedanta; }\end{array}$ & Harious complex problems. Various problems that exist are very \\
& difficult to be solved. Sometimes it is very difficult for humans to \\
focus themselves to find what is really sought in this life so that a & thought arises what is the purpose of humans living in this world? \\
& In this study Vedanta philosophy is able to answer this question. \\
& This study discusses "Human Goals and the Way to Achieving It \\
According to Advaita Vedanta". This research is a qualitative & \\
research Hermeneutics then the data will be analyzed using \\
descriptive and interpretative methods. \\
This study found that the human goal is to achieve happiness, \\
life and alive is a human goal towards a higher goal. In the teachings \\
of Advaita Vedanta it is emphasized that to achieve the highest goal, \\
namely Brahman itself, there are several ways that humans can \\
take, namely: 1). Understanding Life and alive, 2). Understanding \\
Reincarnation is a way to repair bad karma in previous lives in the \\
hope that human goals will be achieved. 3). The four paths to the \\
ultimate goal are: Karma Yoga, Jnana Yoga, Bhakti Yoga and Raja \\
Yoga. Karma yoga is the way to do good actions between humans, \\
helpful and work hard everytimes for the goodness, Jnana Yoga \\
means to achieve the goal from education or knowledgment tha the \\
human is a holly creature, Bhakti Yoga is the way to achieve the \\
goal from the higher lovely to the God than the humans, and Raja \\
Yoga is the way to achieve focuse on mind concentration.
\end{tabular}

\begin{tabular}{|ll|}
\hline Kata Kunci & ABSTRAK \\
\hline Tujuan & Manusia adalah mahluk sosial dan dalam kehidupan \\
Manusia; & sosial sudah pasti manusia memiliki berbagai permasalahan \\
Advaita & yang kompleks. Berbagai permsalahan yang ada sangat sulit \\
\hline
\end{tabular}




\begin{tabular}{|c|c|}
\hline & $\begin{array}{l}\text { untuk diselesaikan oleh sebagian orang bahkan terkadang } \\
\text { manusia sangat sulit untuk memfokuskan dirinya untuk } \\
\text { mencari sesungguhnya yang dicari dalam kehidupan ini } \\
\text { sehingga muncul sebuah pemikiran apakah tujuan manusia } \\
\text { hidup di dunia?. Dalam penelitian filsafat Vedanta mampu } \\
\text { menjawab pertanyaan tersebut. Penelitian ini membahas } \\
\text { mengenai "Tujuan Manusia dan Jalan Untuk Mencapainya } \\
\text { Menurut Advaita Vedanta". Penelitian ini merupakan } \\
\text { penelitian kualitatif Hermeneutika selanjutnya data akan } \\
\text { dianalisis dengan menggunakan metode deskriptif dan } \\
\text { interpretatif. } \\
\text { Penelitian ini menemukan bahwa tujuan manusia } \\
\text { adalah mencapai kebahagiaan, hidup dan kehidupan itu } \\
\text { adalah tujuan manusia menuju sebuah tujuan tertinggi. } \\
\text { Dalam ajaran Advaita Vedanta ditekankan bahwa untuk } \\
\text { mencapai tujuan tertinggi yaitu Brahman itu sendiri ada } \\
\text { beberapa hal jalan yang dapat ditempuh oleh manusia yaitu: } \\
\text { 1). Memahami Hidup dan Kehidupan, 2). Memahami } \\
\text { Reinkarnasi adalah jalan untuk memperbaiki karma buruk } \\
\text { padamasa kehidupanyang terdahulu dengan harapan tujuan } \\
\text { manusia akan dapat tercapai. 3). Empat jalan mencapai } \\
\text { tujuan tertinggi yaitu: Karma Yoga, Jnana Yoga, Bhakti Yoga } \\
\text { dan Raja Yoga. Karma Yoga yakni jalan yang ditempuh } \\
\text { melalui jalan berbuat baik terhadap sesama, saling tolong } \\
\text { menolong dan selalu bekerja untuk hal-hal kebaikkan, Jnana } \\
\text { Yoga yakni mencapai jalan bhakti melalui Jnana atau } \\
\text { pengetahuan bahwa manusia adalah suci, Bhakti Yoga yakni } \\
\text { jalan bhakti yang ditempuh melalui sebuah pengetahuan } \\
\text { cinta kasih yang lebih tinggi terhadap Tuhan dan sesama, } \\
\text { dan Raja Yoga yakni jalan bhakti yang ditempuh dengan cara } \\
\text { meningkatkan konsentari dan mampu mengkonsentrasikan } \\
\text { pikiran. }\end{array}$ \\
\hline
\end{tabular}

\section{PENDAHULUAN}

Segala yang ada di alam ini adalah ciptaan Tuhan dimulai dari manusia, binatang dan juga tumbuh-tumbuhan serta alam semesta isinya. Dari sekian banyaknya yang diciptakan oleh Tuhan hanya manusia sajalah yang merupakan mahluk yang paling sempurna karena hanya manusia yang diberikan akal pikiran sehingga manusia dapat membedakan antara baik dan buruk, benar dan salah. Manusia mempunyai masalah yang kompleks dalam kehidupan ini seperti kebudayaan dan peradaban. Perkembangan manusia sangat pesat dibidang teknologi, sosial, dan budaya. Karakter manusia sangat bermacam-macam karena pola pikir masing-masing.

Gelgel, dkk (1996: 18-19) menyatakan bahwa dalam perkembangan sejarah manusia di Indonesia sering dengan perkembangan kebudayaan, digolongkan kedalam homo sapiens karena masih sangat rendah tingkat kecerdasannya. 
Manusia tertua di Indonesia sudah ada kira-kira jutaan tahun yang lalu waktu dataran sunda masih merupakan daratan dan waktu asia tenggara menjadi bagian benua dan bagian kepulauan masih bersambung menjadi satu. Penduduk dataran sunda sisa-sisanya yang berupa fosil-fosil para ahli antropologi menyebutnya "Phithecanthropus Erectus" yang kemudian dalam puluhan ribu tahun mengalami perkembangan menjadi manusia sekarang ini.

Berdasarkan sejarah perkembangan manusia hingga ditemukannya manusia purba yang paling cerdas. Setelah mengalami perkembangan yakni homo soloensis yang artinya manusia yang cerdas. Ilmu pengetahuan dan teknologi yang dihasilkan manusia dewasa ini menjadi salahsatu bukti betapa pesatnya perkembangan pola pikir manusia hingga saat ini. Disela-sela perkembangan teknologi dan informasi banyak manusia yang berubah menjadi manusia yang modern sehingga berkembang berbagai keinginan manusia yang dapat mempengaruhi sifat dan prilaku manusia menajdi mahluk individu.

Manusia dewasa ini kurang cerdas dalam memanajemen dirinya sendiri sehingga sangat cepat marah walaupun hanya karena masalah yang cukup sepele. Era globalisasi dan modernisasi membuat manusia lupa bahwa mereka sesungguhnya adalah sama dengan manusia yang lainnya dan berasal dari yang satu yaitu Tuhan itu sendiri. Bahkan banyak manusia yang lupa akan keberadaan Tuhan karena sibuk mengejar kesenangannya sendiri bahkan mereka mulai melupakan apa sesungguhnya tujuan manusia itu diciptakan di dunia ini. Manusia mempunyai terlalu banyak keinginan sehingga manusia menjadi sebuah misteri.

Menurut Gabriel Marcel (dalam Watra, 2006: 1-7). Menyatakan manusia itu bukanlah "Problem" yang akan habis dipecahkan melainkan "mystery" yang tidak mungkin disebutkan sifatnya dan cirinya secara tuntas dan oleh karena itu harus dipahami dan dihayati. Dewasa ini banyak yang beralih atau menggali tentang hakekat manusia. Untuk itu maka akan selalu ada pengkajianpengkajian secara filsafat mengenai manusia.

Penelitian ini akan meneliti mengenai "Tujuan Manusia dan Jalan Untuk Mencapainya Menurut Advaita Vedanta" dalam filsafat Vedanta membahas lebih mendalam mengenai tujuan manusia dan jalan-jalan yang harus ditempuh oleh manusia untuk mencapai tujuan yang diinginkan. Peneliti memandang filsafat Vedanta ini sangat penting untuk di bahas agar setiap orang mampu memahami “Tujuan Manusia dan Jalan Untuk Mencapainya Menurut Advaita Vedanta”.

\section{METODE}

Metode sangat menentukan valid atau tidaknya hasil sebuah penelitian. Penelitan yang berjudul "Tujuan Manusia dan Jalan untuk Mencapainya Menurut Advaita Vedanta" adalah sebuah penelitian kualitatif. Menurut Moleong (2010) menyatakan bahwa setiap penelitan kualitatif pasti menghasilkan data deskriptif yang berupa kata-kata ataupun tulisan dapat berupa, buku-buku ataupun jurnal. Pendekatan yang digunakan dalam penelitian ini adalah pendekatan Hermeneutika karena data yang digunakan berupa data teks yaitu teks Weda. Dat yang dignakan dalam penelitan ini ada dua yaitu data primer dan data sekunder. Data primer merupakan data yang diperoleh melalui 
observasi langsung dari lapangan. Sedangkan data sekunder merupakan data yang diperoleh dari buku-buku atau perpustakaan. Sedangkan teknik yang digunakan dalam peneitian ini adalah studi kepustakaan.

\section{PEMBAHASAN}

\subsection{Advaita Vedanta}

Salah satu aliran dari filsafat timur yang paling akhir dijamannya adalah Vedanta Darsana, dalam aliran filsaat Vedanta, Uttara mimamsa atau filsafat Vedanta banyak diulas oleh Bharayana atau Vyasa. Istilah Vedanta secara hapiah adalah intisari atau akhir dari Veda, yaitu ajaran yang terkandung dalam kitab kitab upanisad yang merupakan jnana kanda atau bagian akhir dari Veda setelah mantra, brahmana dan aranyaka (Maswinara, 1999: 175 ).

Vedanta salah satu dari enam aliran filsafat Hindu yang diperoleh oleh sankaracharya, juga disebut dengan nama Uttara Mimamsa, Brahma Mimamsa, Brahma Sutra, karena dipandang sebagai akhir dari veda - veda dengan tofik sentral sebagai jiwa tertinggi, roh kudus universal adalah Brahmana (Pendit, 2009: 224). Titib (1996: 164) menyatakan bahwa kata Vedanta dapat berarti akhir dari veda. Sumber ajarannya adalah kita-kitab upanisad tetapi mengingat kitab-kitab upanisad ini tidak sistematis maka badarayana yang juga disebut maharsi vyasa menyusun kitab yang bernama Vedanta sutra. Vedanta terdiri dari tiga aliran besar yang menjadi pikiran metafisika yang terdiri dari Dvaita, Visistadvaita, dan advaita Vedanta. Dalam penelitian ini peneliti menekankan dan membahas mengenai tujuan manusia menurut advaita Vedanta.

Pendit (2009: 8) menyatakan bahwa advaita merupakan ajaran filsafat Vedanta beraliran monistis, dipelopori oleh sankaracharya. Ajaran ini hanya mengakui adanya satu kebenaran tertinggi,abadi dan tunggal ini diinterprestasikan sebagai Tuhan yang Maha Esa dalam agama Hindu. Ngurah dkk (1999: 131) menyatakan bahwa filsafat Vedanta yang paling popular adalah advaita Vedanta kata "Advaita" berarti bukan dua atau satu tidak dualisme. Sistem ini menyangkal adanya realitas atau kenyataan yang lebih dari satu, tiada suatu yang nyata yang lepas dari Tuhan. Tokoh yang terkenal adalah Sri Sankaracarya. Secara singkat sankara merusmuskan pengertian advaita sebagai berikut: "Barhman" adalah satu-satunya yang nyata, yang tidak rangkap". Seperti yang di jelaskan oleh Sri Sankaracarya bahwa Brahman itu hanya satu yaitu tunggal adanya dan tidak ada duanya.

\subsection{Tujuan Manusia menurut Adwaita Vedanta}

Sesungguhnya stiap mahluk yang diciptakan sudah pasti mempunyaisebuah tujuan terlebih lagi manusia mengingat manusia adalah mahlukciptaan Tuhanyang paling sempurna yang di bekali dengan akal pikiran dan dapat membedakanbanyak hal seperti baikdan buruk. Menurut Advaita Vedanta tujuan manusia tidak hanyalah berada pada satu hal saja yang pada umumnya dikenal oleh umat hindu dengan Moksa. Kaum vedantis mamp mengenal jati dirinya karena mampu membedakan antara yang nyata dan yang tidak nyata sehingga seluruh dunia lenyap baginya. Dunia akan kembali lagi tetapi bukanlahdunia hayalan yang sama. Belenggu kesengsaraan berubah 
menjadi: Sat, Cit, Ananda, Eksistensi yang mutlak, pengetahuan yang mutlak, rahmat kebahagiaan, yang mutlak inilah pencapian dari tujuan Advaita Vedanta (Pendit : 135).

Tujuan manusia dalam advaita Vedanta diatas dimaksud bahwa ketika manusia menyadari hakekat dirinya dan melepaskan belenggu kesengsaraan yang disebabkan pengaruh pikiran dan konsep maya maka manusia akan menemukan suatu pancaran suci dari Brahman, menyadari dirinya sebagai atman yang merupakan bagian dari Brahman menuju Sat, Cit, Ananda, mengetahui segala realitas diri sebagai suatu pengetahuan yang tidak terbatas (mutlak), menyadari keberadaan sang diri (Atman) dan mendapatkan kebahagiaan tanpa ada sesuatu yang dapat berubah itulah hakekat dan tujuan manusia yang sesungguhnya. Dikaji lebih lanjut tujuan manusia sesungguhnya menyadari sang diri sejati sehingga dapat merobek sebuah tirai maya yang menyelimuti Atma yang murni tersebut dan menemukan suatu pengetahuan, kebahagiaan serta eksistensi yang abadi. Manusia perlu mengetahui tujuan hidupnya yang sesungguhnya sehingga tidak terpuruk dalam ruang yang gelap yang tentu diselimuti oleh avidya.

Vedanta memandang bahwa tujuan hidup manusia tidak mesti mensubordinasi individu atas masyarakat, yang bertentangan dengan kemuliaan intrinsik dirinya sebagai pribadi. Tujuan manusia tidak ada dimasa depan dan dicapai ditempat tertentu tetapi Vedanta dengan tegas menyatakan bahwa pemenuhan hidup dapat direalisasikan sekarang dan realisasi spiritual, abhyudaya dan nishreyasa, disini dan sekarang, di dalam badan ini, dunia fana ini adalah tujuan supranatural atau dunia sana. Sepanjang sudut pandang tentang alam adalah materi dan spirit yang komprehensif Vedanta menolak konsep dunia sana. Saat ini manusia adalah atman. Mungkin diri sendiri tidak tahu tetapi ketidak tahuan tidak mampu menghilangkan kebenaran itu. Tidak hanya nanti atau di masa depan manusia menyatu dengan Brahman, tetapi sekarang dan disini dan kenyataannya menusia selalu satu (Suwantana, 2011 : 5).

Menurut sankara kelepasan dari samsara merupakan penggabungan mutlak sang roh berbeda dengan Brahman. Disebabkan dugaan dari salah satu roh berbeda dengan Brahman. Menurut sankara karma dan bhati adalah cara menuju jnana yang merupakan moksa (Maswinara, 1999: 183 ). Dilihat dari pernyataan sankara tersebut ia sangat memegang teguh konsep identitas tanpa suatu perbedaan riil dan berusaha menggunakannya secara logis dalam segala hal karena ia menerima tanpa ragu-ragu identitas jiwa dan Tuhan yang diajarkan secara berulang-ulang dalam kitab-kitab upanisad.

Berdasarkan pemaparan diatas sesungguh yang menjadi tujuan dari advaita Vedanta itu sendiri adalah kembali kepada Brahman, untuk kembali kepada Brahman itu sendiri banyak hal yang harus dilakukan menurut ajaran advaita Vedanta yaitu manusia harus memahami hidup dan kehidupan terlebih dahulu, reinkarnasi serta empat jalan meuju kedasaran tertinggi.

\subsubsection{Memahami Hidup dan Kehidupan}

Sesungguhnya manusia yang adadi dunia ini hidup dalam sebuah kehidupan. Manusia bukan hanya sekedar hidup dialam ini dan menjalani kehidupan. Secara alami manusia ingin mengetahui mengapa ia hidup dan 
mengapa harus menjalani sebuah kehidupan ini. Hidup adalah sesuatu hal yang perlu dimaknai dan kehidupan merupakan sebuah perjalanan yang diselusuri dan mesti dipahami oleh manusia, sehingga manusia menyadari hakekat hidup dan kehidupan ini. Krisna mengajarkan bahwa seharusnya manusia hidup di dunia ini seperti daun teratai yang hidup di air tetapi tidak pernah basah; manusia hidup didunia tetapi hatinya tetap pada Tuhan dan tangannya tetap pada pekerjaan (Ghindwani, 2005: 92). Ajaran ini menekankan sudah seharusnya manusia memiliki rasa cinta kepada Tuhan, hidup di jalan dhrama, akan membuat manusia menjauh dari avidya. Menurut ajaran Vedanta menjalani hidup dan kehidupan tidak hanya berdasarkan sebuah teori semata tetapi perlu sebuah aplikasi. Vedanta yang bersifat praktis jika dilaksanakan maka manusia akan menuju kehidupan yang lebih tinggi. Advaita menginginkan manusia perlu memiliki kehidupan yang tenang dan damai.

Manusia menjalani hidup secara berjenjang untuk mencapai keadaan yang tinggi tersebut. Hidup manusia di sebabkan karena adanya partikel kesadaran sehingga roh menghasilkan kesadaran mengalami kehidupan. Ajaran yang paling mulia dari advaita adala ketika mampu memberikan pemahaman bahwa manusia hidup dari kesadaran yang paling murni, sehingga manusia harus mencari kedalaman dirinya, dan mengnal dosa selama manusia hidup di dunia, ajaran ini hanya mengenal kesalahan. kesalahan terbesar bagi advaita ketika manusia menganggap dirinya sebagai orang yang lemah, pendosa selama hidupnya. Menurut Vedanta aktivitas manusia dilaksanakan atas kehendak dari partikel kehidupan yang memiliki kesadaran yang kemudian diterjemahkan melalui kecerdasan danpikiran ke badan manusia (Singh,2003:23).

Vedanta selalu mengajarkan ke universalan untuk menjalani hidup, agar manusia senantiasa menciptakan kedamaian di dunia. ketika manusia memberikan pelayanan terhadap sesama selama hidupnya maka ia pantas si sebut karmin orang yang bekerja tanpa terikat pada hasil. Pada akhirnya manusia akan paham bahwa hiduplahsebaik mungkin segeralah sadar bahwa semua ini maya, kehidupan ini adalah sebuah proses untuk mencapai tujuan tertinggi, maka berbuatlah sebaik - baiknya memfokuskan diri kepada Tuhan, bekerja, dan melakukan sesuatu dengan sungguh-sungguh tanpa mengikat diri.

\subsubsection{Reinkarnasi: Perjalanan Menuju Tuhan menurut Adwaita Vedanta}

Reinkarnasi atau kelahiran kembali adalah salah satu dari dasar keyakinan umat Hindu. Reinkarnasi adalah sebuah jalan kelahiran kembali berdsarkan karma atau perbuatan yang telah dilakukan oleh seseorang pada kehidupan masa lalunya, dan reinkarnasi adalah tujuan manusia dilahirkan untuk menyelesaikan atau membayar karma-karma buruknya yang telah dilakukan pada masa kehidupan masa lalunya. Karena sesungguhnya manusia itu tidak pernah mati akan tetapi yang mati hanyalah badan kasarnya saja ketika badan kasarnya telah rusak maka akan digantikan dengan badan yang baru. Menurut advaita Vedanta proses reinkarnasi/kelahiran kembali semua itu adalah kerikat dengan ego yang mempengaruhi roh sehingga dapat terjadi kelahiran berulangulang. Pernyataan pertama tentang hukum reinkarnasi, dalam sejarah dunia terdapat dalam kitab Rg Veda, namun bagsa mesir kuno juga menunjukkan adanya kecendrungan membenarkan adanya kelahiran kedua. Sejarahwan 
Yunani henrodotus mengatakan bahwa bangsa mesir kuno meyakini adanya jiwa abadi yang terpisah dari tubuh. Ide tentang reinkarnasi ini kemudian diambil oleh filsuf yunani Plato dan aristoteles. Plato mengajarkan keberadaan jiwa abadi yang mengalami kelahiran berulang-ulang (Anandas, 2007: 39).

Manusia melekat dengan sebuah kehidupan yang bersifat duniawi, kemelekatan pada kehidupan ini membuktikan bahwa ada pengalaman dan keberadaan masa lalu dan ada kehidupanmasa depan. Kesadaran badan menyebabkan penderitaan yang tidak terhingga. Kesadaran badan akan lenyap apabila mansia telah mengembangkan kesadaran Tuhan (Anandas, 2007: 41). Manusia diharapkan sedikit demi sedikit melepaskan keterikatan yang berlebihan sebab itulah asal dari penderitaan. Sepanjang manusia belum menyadarinya manusia tetap menjunjung tinggi hidup material dan bersifat keduawian. Advaita bermaksud untuk mengajak manusia untuk sadar memahami dirinya sendiri untuk memutuskan penderitaan. Minimal manusia menjalankan kebenaran dan mendasari kepercayaannya kepada Tuhan. Berdasarkan pemaparan diatas dapat disimpulkan bahwa reinkarnasi adalah sebuah jalan menuju tuhan karena melihar dari tujuan reinkarnasi menurut advaita Vedanta sendiri adalah untuk membayar segala perbuatan buruk yang dilakukan pada masa kehidupan yang terdahulu dan memperbaiki moral setelah semua karma buruk bersih dari badan kita maka niscaya setiap orang akan mampu kembali kepada tujuan utamanya yaitu Tuhan itu sendiri.

\subsubsection{Empat Jalan Menuju Tuhan Menurut Advaita Vedanta}

Menurut ajaran Adwaita Vedanta ada empat jalan menuju Tuhan yang disebut dengan Catur Yoga Marga. Catur Yoga Marga pada tahap awal yang dijelaskan adalah Bhakti Karma Yoga, Jnana Yoga, Bhakti Yoga dan raja Yoga. Keempat ajaran yoga ini dapat di uraikan sebagai berikut :

\section{Karma Yoga}

Karma berasal dari bahasa Sangskerta yaitu dari urat kata ' $k r^{\prime}$ yang artinya berbuat. Karma adalah perbuatan. Setiap manusia dalam kehidupan ini sudah pasti berbuat. Tujuan akhir dari manusia adalah pengetahuan (Kesadaran). Kenikmatan manusia bukanlah tujuan akhir dari manusia selain pengetahuan. Penyebab dari semua penderitaan yang dialami seseorang di dunia ini adalah bahwa seseorang itu sendiri dengan bodoh berpikir bahwa kenikmatan adalah tujuan yang harus dicari. Semua tindakkan yang dilakukan baik ritual maupun gerak yang dilakukan oleh manusia memiliki suatu penjelasan dari perspekti filsafat. Begitu pula dengan ajaran karma yang dimiliki filsafatnya sendiri.

Gerak manusia yang menghasilkan karma dapat ditinjau dari tindakkan manusia dalam kehidupan sehari-hari misalnya melakukan pelayanan terhadap siapaun adalahsuatu hal yang mulia merupakan bagian dari perbuatan dharma. Berbuat terhadap sesama manusia merupakan sebuah perbuatan yang mencerminkan sebuah perbuatan yang menunjukkan sebuah sikap menunjukkan rasa Bhakti kehadapan Tuhan karena telah ikut memelihara dan melindungi ciptaan-Nya sehingga muncul sebuah pemahaman bahwa manusia yang atu dengan manusia yang lainnya adalah sama merupakan bagian dari Brahman itu sendiri. 
Jika manusia melaksanakan karma yoga tanpa menafsirkan yang salah dimana manusia harus senantiasa berpikir dalam berbuat janganlah pernah memikir akan hasil dari sebuah perbuatan baik yang telah dilakukan. Apabila manusia mampu membebaskan diri dari kerikatan sebuah hasil maka sama dengan melaksanakan Bhakti kehadapan Tuhan itu sendiri. Biarkan semuanya berlalu; pikiran terpusata pada kerja dan bekerjalah terus namun jangan biarkan gelombang itu menaklukkan pikiran. Bekerjalah dengan tiada putusnya namun jangan ikatkan dirimu pada pekerjaan itu. Keterikatan itu sangat menakutkan (Vivekananda, 2001:141). Orang yang melakukan perbuatan baik adalah mereka yang melakukan sebuah perbuatan tanpa mengaharapkan sebuah hasil atau tanpa motif apapun untuk mendapatkan uang. Jika seseorang mampu melakukannya maka ia dalam sifat itu, karena akan ditransformasikan pada dunia. Orang seperti ini mewakili figur paling ideal dalam karma yoga (Vivekananda, 2001: 157).

Advaita menyatakan bahwa sebagai manusia bekerjalah secara totalitas, fokuskan pikiran. Pada dasarnya kekuatan dan kesaktian akan muncul dari keterikatan. Sebagai contoh ketika seseorang beepikir ingin bekerja berbuat baik kepada seseorang tapi ada kemungkinan besar, orang yang dibantu akan berkhianat hingga menimbulkan rasa sakit. Pemikiran seperti ini membuat manusia tidak ingin mengerjakan sesuatu karena takut akan merasakan penderitaan dan sakit hati. Ajaran karma yoga lebih menekankan kerja tanap mengharapkan sebuah hasil. Setiap perbuatan manusia yang mementingkan diri sendiri sebenarnya menghambat manusia untuk mencapai sebuah tujuan. Bekerja tanpa mementingkan diri sendiri yang akan mengantarkan manusia menuju kepada tempat tutuan yang sesungguhnya (Pendit, 2005 : 104). Kerja merupakan bagian dari pada yoga. Karena setiap kerja yang dilakukan pasti membutuhkan focus yang baik karena jika bekerja dengan focus maka tidak ada sebuah keragu-raguan dalam diri. bekerjalah dengan kesungguhan hati dan lakukan pekerjaan tanpa keluhan sedikit pun karena kerja adalah sebuah kewajiban bagi setiap manusia. Kerja adalah sebuah kewajiban karena Tuhan pun tidak berhenti bekerja agar alam ini tetap berputar.

\section{Jnana Yoga}

Dalam Advaita Vedanta jnana merupakan sebuah pengetahuan tentang sang diri sejati, sang Atman, Brahman yang dapat diketahui melalui ajaran agama, pengetahuan melalui kitab suci. Perjalanan menuju sebuah pembebasan yang merupakan tujuan manusia salah satunya melalui jalan jnana yoga dimana hakekat sang diri sejati dipertanyakan kemudian diketahui dengan benar. Menyadari sang diri berada dalam setiap individu. Pengetahuan suci itu dapat diketahui dan disadari ketika manusia masuk ke dalam dirinya sendiri. Yoga mengajarkan persatuan antar mahluk dan bahwa masing-masing diri manusia adalah Tuhan yang termanifestasikan di Bhumi (Ghindwani, 2005:119). Ajran Jnana Yoga mendasarkan pada hakekat pengetahuan alam semesta yang Nampak seperti atom adalah Tuhan itu sendiri yang menjadi dasar kehidupan manusia. Semua mahluk baik yang paling kecil hingga besar, manusia atuapun hewan adalah manifestasi Tuhan yang sama. Jnana Yoga mengarahkan manusia untuk mengetahui Tuhan itu sendiri, mebuktikan Tuhan hingga dapat diyakini. 
Pengetahuan tentang Tuhan didasari dengan keyakinan dalam beragama pula. Manusia perlu kesadaran untuk memasuki ranah yang trasenden tersebut.

Apakah bukti adanya Tuhan? Persepsi secara langsung atau pramana. Bukti adanya dinding ini adalah bahwa aku dapat mengamatinya. Tuhan telah diamati oleh ribuan orang sebelumnya dan akan dapat diamati oleh mereka yang ingin mengamatinya. Namun ini bukanlah presepsi indrani sama sekali. itu membawa manusia mampu mengatasi indra-indra. Agama sejati sepenuhnya untuk mengatasi indra. Bahkan ulat kecil pun suatu saat akan mampu mengatasi indranya dan akan mencapai Tuhan. Tidak ada kehidupan yang gagal; tak ada yang namanya kegagalan di dunia ini. Jika seratus kali manusia menyiksa dirinya dengan keterikatan ini maka seribu kali ia harus berjuang dan akhirnya ia pun akan menyadari bahwa ia adalah Tuhan (Vivekananda, 2001 : 177-178).

Memahami dan menjadi seseorang yang ingin menjalani jnana yoga juga harus belajar bagaimana mengenal diri sejati sebagai manusia. Di dalam pencarian sang diri sejati akan menemukan suatu pemahaman untuk menjadi seorang jnana yoga yang utuh. Seperti yang telah dijelaskan sebelumnya jika manusia mampu mengenal dirinya sebagai Tuhan itulah suatu tujuan yang ingin disampaikan secara universal oleh advaita Vedanta. Semakin manusia melihat kedalam dirinya akan semakin mengetahui apa yang ada dalam dirinya, bukanlah sosok badan ini yang sejati terjaditetapi didalam badan itulah sesungguhnya sejati. Jika seseorang mau mengajarkan pengetahuannya untuk meningkatkan daya kenikmatan indrani maka akan bayak yang tersedia. Namun jika seseorang mau berusaha untuk menunjukkan tujuan tertinggi maka hanya sedikit yang akan mendengarnya. Semakin sedikit kemampuan untuk memahami yang lebih tinggi maka semakin sedikitlah kesabaran untuk mencapai-Nya.

\section{Bhakti Yoga}

Umat Hindu pada umumnya bhakti yoga merupakan salah satu pilihan utama karena umat Hindu kerap melalukan kegiatan beragamanya dengan menggunakan sarana dan prasana seperti bunga, dupa, buah, air dan sebagainya. Bhakti marga sebenarnya sangat identik dengan bhakti yoga istilah bhakti marga yoga dimaksudkan untuk lebih menekankan bahwa bhakti adalah jalan dan sekaligus juga sarana mempersatukan manusia dengan Tuhan. (Ngurah,dkk,1999:79). Dalam ajaran advaita Vedanta lebih menekankan bhakti yoga dengan menekankan cinta kasih yang sangat mendasar. Bhakti yoga adalah jalan bagi orang yang bersifat emosional, sang pencipta, ia ingin mencintai Tuhan karena ia menggunakan semua jenis ritual. Manusia melihat cinta kasih dimanamana dialam ini. Apapun yang merupakan kebaikkan, keagungan, dan kemuliaan adalah hasil dari cinta kasih.

Bhakti yoga adalah pengetahuan tentang cinta kasih yang lebih tinggi. Ia menunjukkan kepada manusia bagaimana cara mengendalikannya bagaimana cara menanganinya, menggunakannya, member tujuan baru, dan dengannya kita akan memperoleh hasil tertinggi dan mulia yaitu bagaimana membuatnya dapat menghantarkan manusia pada perberkatan spiritual "kasihilah cintailah yang tertinggi". Segala sifat rendah akanhilang dari dirinya karena objek yang 
dicintainya adalah objek tertinggi (Vivekananda, 2001:184). Bhakti yoga mengajarkan cara mencintai tanpa motif tertentu, mencintai Tuhan, mencintai kebaikkan demi cinta itu sendiri, bukan karena apapun. Bhakti yoga juga mengajarkan bahwa cinta itu sendiri adalah buah tertinggi dari cinta.

Pada awalnya cinta kasih itu adalah untuk sang diri namun karena tuntunan dirinya membuat cinta kasih itu memiliki pamrih. Pada akhirnya datanglah cahaya terang, ketika sang diri sudah tidak terbatas. Manusia sendiri juga mengalami sebuah perubahan. Dia akan mendekati Tuhan. Membuang segala keinginan sia-sia, dimana sebelumnya ia pernah dengan keinginankinginan itu. Bersamaan hilangnya keinginan itu maka sirnalah pula ke egoisan, dan pada puncaknya dia akan menemukan bahwa cinta kasih pecinta dari yang di cinta adalah sama.

\section{Raja yoga}

Sebagian besar orang menganggap bahwa ajaran raja yoga adalah ajaran yang paling sulit untuk ditempuh. Raja yoga dipandang sebagai jalan tertinggi sebab syarat utamanya mampu mengkonsentrasikan pikiran. Suatu metode atau cara untuk mengendalikan diri yang berpusat pada kuda-kuda pikiran manusia. Sebenarnya raja yoga adalah pokok ajaran yang focus pada pengedalian diri itu sendiri. Yoga adalah sebuah penhetahuan yang mengajarkan manusia bagaimana mendapakan pengalaman masa lampau dan religius. Manusia menginginkan mendapatkan pengalaman masa lampau dan religius. Manusia menginginkan kebenaran, ingin mengalami sendiri kebenaran itu. Jika ia telah memahami, menyadari, merasakannya dalam hatinya maka dengan sendirinya semua keraguan akan sirna, semua kegelapan akan hilang dan semua yang bengkok akan dibuat lurus, kata kitab suci veda. Pengetahuan raja yoga berusaha menyajikan sebuah metode praktis dan ilmiah pada manusia untuk mencapai kebenaran. Tujuan akhir dari raja yoga adalah bagaimana mengkonsentrasikan pikiran, kemudian mencapai keadaan istirahat yang terdalam (alam bawah sadar) dari pikiran itu sendiri, lalu meyatakan isinya secara umum dan membuat kesimpulan darinya. Pikiran itu tak pernah menanyakan apa agma seseorang yang terpenting dari diri sendiri dan orang lain adalah manusia, itu sudah cukup (Vivekananda, 2001:205).

Menjadi seorang yogi harus selalu berlatih. Untuk melaksanakan yoga itu sendiri harus melalui berbagai tahapan, mulai dari yang paling dasar hingga tinggkat yang paling tinggi. Yang pertama adalah pengendalian emosi, kemudian yang kedua adalah konsentrasi, meditasi dan terakhir menyeimbangkan pikiran sebagai bentuk yoga. Semakin kuat daya konsentrasi semakin banyak pengetahuan yang diperoleh konsentrasi itu adalah cara yang paling baik untuk memusatkan pikiran melalui konsentrasi penuh terhadap apa yang menjadi fokusnya. Dari pemaparan diatas maka raja yoga cara untuk mengendalikan pikiran.

Demikianlah empat yoga yang dapat di jadikan sebuah pedoman untuk mencapai tujuan manusia yang paling hakiki. Dengan hati yang murni, suci dan keyakinan penuh maka apapun jalan yang dapat ditempuh dari keempat yoga tersebut maka akan membawa manusia kea lam kesadaran murni dimana manusia akan mencapai kesadaran dan menyamakan diri dengan sang Brahman. 


\section{PENUTUP}

Tujuan manusia menurut Advaita Vedanta mengajarkan bahwa manusia harus memiliki sebuah usaha dalam mencapai tujuannya seperti yang digambarkan dalam Advaita Vedanta. Tujuan manusia dalam AdvaitaVedanta adalah mencapai pengetahuan, eksistensi dan kebahagiaan yang mutlak. Semua itu adalah pencapaian kepada yang maha tinggi yaitu Tuhan. Adapun beberapa jalan yang harus diketahui agar tujuan itu tercapai. menurut ajaran advaita Vedanta yaitu : 1). Manusia harus memahami hidup dan kehidupan, kehidupan ini adalah sebuah proses untuk mencapai tujuan tertinggi, maka berbuatlah sebaik - baiknya memfokuskan diri kepada Tuhan, bekerja, dan melakukan sesuatu dengan sungguh-sungguh tanpa mengikat diri. 2). Reinkarnasi adalah sebuah jalan yang dimiliki oleh manusia untuk memperbaiki hasil-hasil karmanya dengan tujuan sampai pada tujuan akhirnya yaitu Tuhan. serta 3). empat jalan meuju kedasaran tertinggi dalam Advaita Vedanta adalah karma yoga yakni jalan yang ditempu melalui jalan berbuat baik terhadap sesame, saling tolong menolong dan selalu bekerja untuk hal-hal kebaikkan, jnana yoga yakni mencapai jalan bhakt melalui Jnana atau pengethuan bahwa manusia adalah suci, Bhakti Yoga yakni jalan bhakti yang ditempuh melalui sebuah pengetahuan cinta kasih yang lebih tinggi terhadap Tuhan dan sesama, dan Raja Yoga yakni jalan bhakti yang ditempuh dengan cara meningkatkan konsentari dan mampu mengkonsentrasikan pikiran.

\section{DAFTAR PUSTAKA}

Gelgel, I Putu, Dkk. 1996. Sejarah Kebudayaan. Proyek Penyetaraan DII Guru SDAgama Hindu. Denpasar : Departemen Agama.

Ghindwani, Hira D.2005. Hindu Agama Universal Bunga Rampai Pemikiran dan Kisah Swani Vivekananda. Denpasar : Media Hindu.

Maswinara, I Wayan. 1999. Sistem Filsafat Hindu (Sarva Darsana Samgraha). Surabaya : Paramitha.

Moleong, Lexi J. 2004. Metodelogi Penelitian Kualitatif. Bandung : Remaja Rosdakarya.

Ngurah, I Gusti Made dkk. 1999. Buku Pendidikan Agama Hindu Untuk Perguruan Tinggi. Surabaya : Paramitha.

Pendit, S Nyoman. 2009. Glosari Sanskerta. Denpasar : Sarad.

Ra, Anandas. 2007. Reinkarnasi Hindup Tak Pernah Mati. Surabaya : Paramitha.

Swantana, I Gede. 2011. Petikan Dawai Vedanta. Indra Udayana Institut Of Vedanta:Asrham Gandhi Puri.

Titib. I Made. 1996. Veda Sabda Suci. Surabaya : Paramitha.

Watra, I Wayan. 2006. Filsafat Manusia dalam Persfektif Hindu. Surabaya : Paramitha. 